\title{
Appropriate sampling strategy and analytical methodology to address contamination by industry. Part 2: Geochemistry and speciation analysis
}

Review Article

\author{
Aurela Shtiza*, Rudy Swennen \\ Katholiele Univeriteit of Leuven, \\ Geo Institute, Celestijnenlaan 200E, \\ B-3001 Heverlee, Belgium
}

Received 15 April 2010; accepted 2 October 2010

\begin{abstract}
The degree of contamination in soils, sediments and dusts can be assessed based on knowledge of a variety of factors, such as industrialization, type of contaminants, deposition conditions, contamination-control techniques, along with the characteristics of the recipient environmental compartments, which include pathways for contamination transport, depth of infiltration, and degree of groundwater contamination. The impact of contaminants also depends on the quantity, mobility and speciation of contaminants/wastes as well as on the sensitivity of the recipient compartments. With sufficient knowledge of these factors, a number of conclusions can be drawn concerning the status of contamination in industrialized areas. This literature review aims to scrutinize some of the methods used to analyse the occurrence, speciation, mobility, bioavailability and likely the toxic effects of contaminants in the environment.
\end{abstract}

Keywords: single extractions $\cdot$ sequential extraction $\cdot \mathrm{pH}_{\text {stat }} \cdot$ leaching $\cdot$ mobility $\cdot$ speciation $\bullet$ industrial contaminants

(C) Versita Sp. z o.o.

\section{Introduction}

The intensive industrial production and transformation of ores and metals, and particularly, the transportation and storage of contaminants/wastes in the environment in the last hundred years have produced large quantities of waste. Erosion and weathering of contaminated soils and wastes results in the release of heavy metals and metalloids into nearby rivers and sediments [1]. To

*E-mail: aurela_shtiza@yahoo.com; Tel: +3292417738; Fax: $+3292424445$ investigate the pollution levels and the mobility of the heavy metals and metalloids classical and/or innovative techniques can be used [2]. To measure contamination levels and assess heavy metal mobility is a challenging task because many factors affect the occurrence and the mobility of heavy metals, such as $\mathrm{pH}$, solubility, cation exchange capacity, presence of clays, acid/base neutralizing capacity of soils/sediments, and so on. The selection of an appropriate conceptual sampling model requires that the entire surface under investigation is characterized accurately and any 'hot spots' are properly represented in the sampling inventory [3].

The development of a conceptual model and the selection of appropriate sampling media for characterization of con- 
taminants were addressed in the first part of this article [4]. Once the sampling types are selected and collected, the measurement protocols are applied. An analytical protocol is a specific procedure to make observations, determine the characteristics, and conclusions for each sample or for a group of samples [5]. Analytical chemistry has become the science that does not just provide the results, but the best strategy to measure chemical properties of various sampling media. Selection of appropriate sampling types, sample collection, sample pre-treatment and chemistry analysis are the main subsequent steps that will infer the contamination in a specific site [6]. The aim of this literature review is to summarize and address the advantages and pitfalls of: the key steps in sample pretreatment; the general characterization of the sample; the selected methods that are used to assess mobility and speciation of contaminants in past or present industrial sites. To address the speciation, the example of chromium $(\mathrm{Cr})$ is used due to the different toxicities related to the different chromium species $\mathrm{Cr}(\mathrm{III})$ versus $\mathrm{Cr}(\mathrm{VI})$.

\section{Analytical protocols}

Environmental samples collected in one contaminated site have the main contaminant(s) in common, but are heterogeneous with respect to the amount of the contaminant(s) they contain. This can be explained with the heterogeneity and the physico-chemical composition of the sample. The influences of sampling and sample pre-treatment on the final results are of major concern in environmental chemistry, therefore they shall be described in detail [4, 79]. An important step after sampling is the pre-treatment and selection of the most appropriate analytical protocols to be applied in order to characterize the contaminant chemical reactivity, speciation, retention, leaching, (bio)availability and mobility. Choosing the most appropriate analytical technique requires an understanding on how the contaminants are binding and the conditions under which they will be released into the environment [8]. Some of the commonly used techniques used generally in environmental studies to characterize heavy metal concentrations and mobility will be scrutinized.

\subsection{Sample pre-treatment}

Sediments often play an important role in maintaining the water quality by removing contaminants from the water column. However, subsequent contaminant remobilization from the sediment can result in elevated dissolved concentrations long after the initial source has been removed. The manner in which contamination is treated ultimately depends on the particle reactivity [10].

The quantity of the samples to be collected in the field will depend mainly on the type of analytical protocols to be applied. Even after taking into account that some sample loss might occur due to sample pre-treatment, generally for total concentration analysis only a few grams of soils/sediments/dusts are required. If additional analytical protocols are to be applied on the samples such as sequential extraction, $\mathrm{pH}_{\text {stat }}$, X-Ray Diffraction (XRD) more sample will be required. Is important to know that not all the samples will be analyzed with all the techniques available due to the large costs and time this will require. Generally for soils and sediments where different techniques will performed a quantity of $1-2 \mathrm{~kg}$ of sample is recommended to be collected. After transportation to the laboratory, the pre-treatment of the samples consists in room temperature drying or oven drying for three days at $40^{\circ} \mathrm{C}$, if the latter does not affect the reactivity of the samples. There are some concerns regarding how the sample pre-treatment affects the speciation and the mobility of the heavy metals and/or major elements [11$15]$ as well as organic carbon distribution in various soil fractions [16].

Disaggregation by rolling, homogenization, sieving and coning preceded the quartering [9]. The fraction below $2 \mathrm{~mm}$ is manually crushed in a porcelain mortar. According to Wagner et al. [17], the "disaggregation" of the samples by rolling' in a porcelain mortar and 'coning and quartering' ensure a more representative homogeneous powder sample than samples crushed mechanically, or split by a 'spine riffler'. The fine powder obtained from mechanical crushing is transferred into glass flasks prior to analysis, whereby the rest of the sample below $2 \mathrm{~mm}$ is put in plastic bags and kept at room temperature and dry conditions for any further analysis (extractions, $\mathrm{pH}_{\text {stat }}$, mineralogical determinations, etc. ...). Figure 1 indicates the subsequent steps from sample collection until sample treatment.

\subsection{Sample characterization}

\subsubsection{Solid matrix (Soil/sediment, dust samples)}

Guidelines for soil description from FAO [18] can be used as an excellent manual for the characterization of properties for solid matrix samples (soils/sediments and dusts). Although this guideline is not directly intended for characterization of contaminated/polluted sites the initial assessment can be approached in the same way. The color of solid matrix samples (soils, sediments and dusts), $\mathrm{pH}$, cation exchange capacity (CEC), grain size, organic carbon (OC) are only some of the key parameters for solid matrix samples that can be determined in order to give a clear overview on the conditions controlling the mobility 


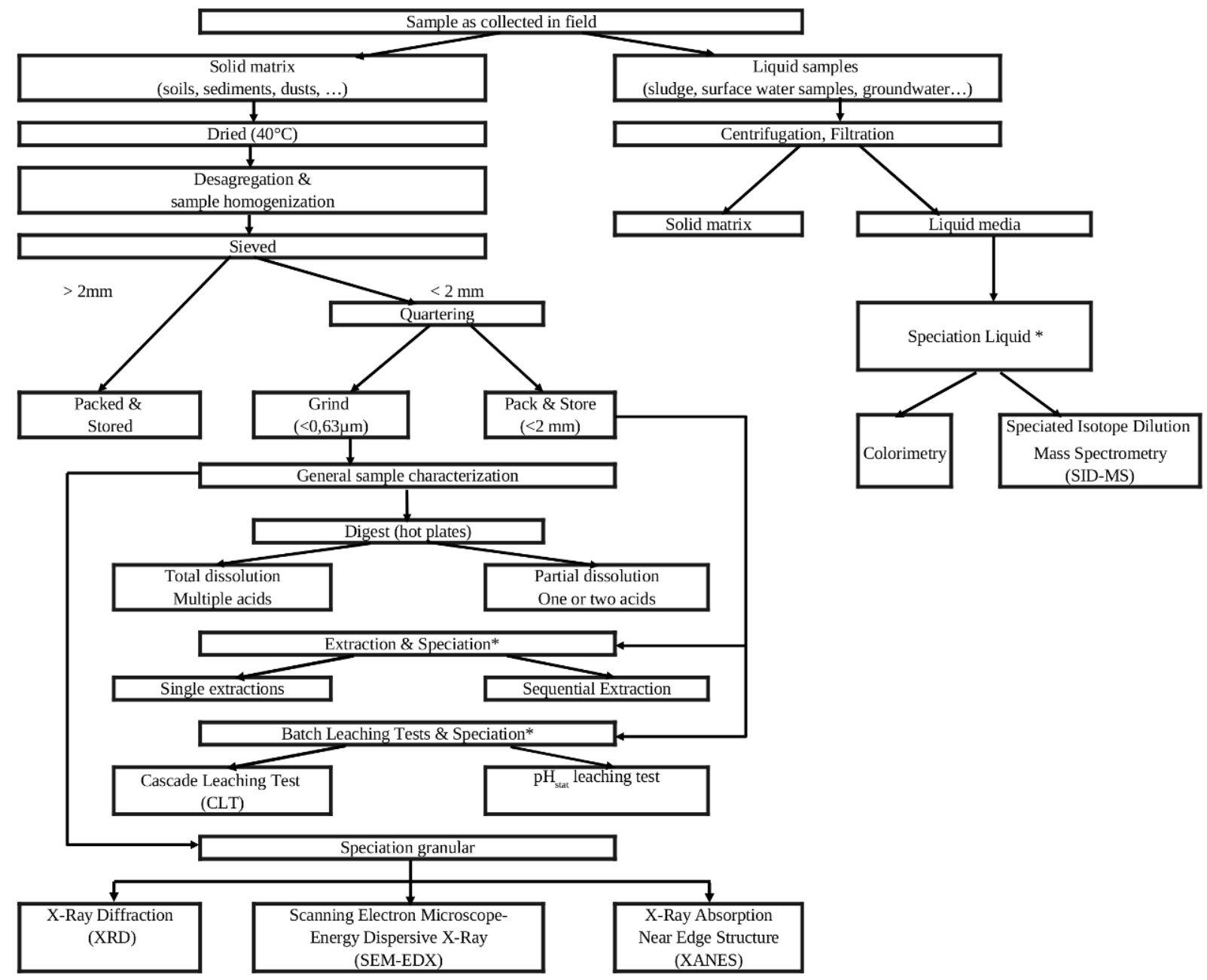

Figure 1. Schematic view of the sample treatment, geochemical and speciation protocols that can be applied on various samples. ${ }^{*}$ Speciation using the methods reported for liquid media.

of contaminants [2].

Soil color reflects the composition as well as the past and present oxidation-reduction conditions of the soil. It is generally determined by coatings of very fine particles of humified organic matter (dark), iron oxides (yellow, brown, orange and red), manganese oxides (black) and others, or it may be due to the color of the parent rock. The color of the soil matrix of each horizon should be recorded in the moist condition (or both dry and moist conditions where possible) using the notations for hue, value and chroma as given in the Munsell soil color charts [19]. Hue is the dominant spectral color (red, yellow, green, blue or violet), value is the lightness or darkness of color ranging from 1 (dark) to 8 (light), and chroma is the purity or strength of color ranging from 1 (pale) to 8 (bright). Where there is no dominant soil matrix color, the horizon is described as mottled and two or more colors are given. In addition to the color notations, the standard Munsell color names or codes may also be reported $[18,19]$.

$\mathrm{pH}$ (short for potentiometric hydrogen ion concentration) is the measure for acidity or basicity of a solution. When the $\mathrm{pH}$ is measured in the field, the method used should be indicated on the field data sheet. The field soil $\mathrm{pH}$ should not be a substitute for a laboratory determination and should be correlated with laboratory determinations where possible [18]. In the field, $\mathrm{pH}$ is either estimated using indicator papers, indicator liquids (e.g. Hellige), or measured with a portable $\mathrm{pH}$ meter in a soil suspen- 
sion $(1$ part soil and 2.5 parts $1 \mathrm{M} \mathrm{KCl}$ or $0.1 \mathrm{M} \mathrm{CaCl}$ solution). After shaking the solution and waiting for 15 minutes, the $\mathrm{pH}$ value can be read [18]. Soil $\mathrm{pH}$ in the laboratory should always be measured after instrument calibration with known standard buffers, as a check on the functioning of the measurement system and in order to provide reliable results from different operators. The calibration should be performed using two buffers whose values bracket the expected value of the samples being measured. It is essential that the difference between the two calibration buffers should be no more than $2-3 \mathrm{pH}$ units apart (generally buffers at $\mathrm{pH} 4$ and 7 are used). $\mathrm{pH}$ in laboratory is measured in a suspension of $10 \mathrm{~g}$ soil/sediment in $25 \mathrm{ml}$ deionized water or $1 \mathrm{M} \mathrm{KCl}$ or $0.1 \mathrm{M} \mathrm{CaCl}_{2}$, after magnetic stirring for 30 minutes and five minutes sediment settling for stable reading values. An overview of various techniques used for $\mathrm{pH}$ measurement is summarized in Buck et al., [20] FAO [18]. $\mathrm{pH}$ is one of the main controlling parameters of the mobility of heavy metals (in general mobility of heavy metals increases when the $\mathrm{pH}$ decreases, while for $\mathrm{Cr}$ this depends highly on its speciation).

Effective cation exchange capacity (ECEC/CEC) in the Glossary of Soil Science Terms [21] is defined as the sum of exchangeable cations that a soil, soil constituent (i.e. clay) or other material can adsorb at a specific $\mathrm{pH}$. The main sources of cation exchange in soils are clay minerals, organic matter and amorphous minerals. CEC is highly dependent upon soil texture and organic matter content. In general, the more clay and organic matter in the soil, the higher the CEC. Clay content is important because these small particles have a high ratio of surface area to volume. Different types of clays also vary in CEC. Smectites have the highest CEC (80-100 meq $\left.100 \mathrm{~g}^{-1}\right)$, followed by illites (15-40 meq $100 \mathrm{~g}^{-1}$ ) and kaolinites (3-15 meq $\left.100 \mathrm{~g}^{-1}\right)$. There are two standardized methods used to determine the CEC: 1 . "silver thiourea method" and 2. ammonium acetate method also known as one-step centrifugal extraction [22]. These methods consist in replacing the normal mixture of cations on the exchange sites with a single cation such as ammonium $\left(\mathrm{NH}_{4}^{+}\right)$, to replace that exchangeable $\mathrm{NH}_{4}^{+}$with another cation, and then to measure the amount of $\mathrm{NH}_{4}^{+}$exchanged (which was how much the soil had held). More commonly, the soil testing labs estimate CEC by summing the calcium, magnesium and potassium measured in the soil testing procedure with an estimate of exchangeable hydrogen obtained from the buffer $\mathrm{pH}$. Generally, CEC values arrived at by this summation method will be slightly lower than those obtained by direct measures.

Particle (grain) size is a measurement of the size distribution (i.e. fractionation) of individual particles in the solid samples [23]. Soil particles smaller than $2000 \mu \mathrm{m}$ are generally divided into three major groups: sands, silts (loam) and clays. The textural class of the different sampling media (soil and sediments) depends on the percentage of each group. Systematic grain size analysis can be carried out on specific bulk samples in order to obtain information on grain size distribution. There are six different methods (1. sieving, 2. microscopic examination, 3. sedimentation, 4. gravitational settling examination, 5. cascade impaction, 6. laser scattering diffraction) under the OECD-110 or OPTTS 830.7520 guidelines for the determination of the grain size. The purpose of including all these guidelines under one single document is to minimize the variations among the testing procedures that must be performed to meet the requirements of the European Chemical Agency (ECHA) or US Environmental Protection Agency (USEPA) for pure substances. However, for heterogeneous matrixes, such as contaminated contaminated soils/sediments/dusts the task of conducting grain size analysis becomes very challenging [9]. The general principles of conducting grain size analysis on soil/sediment are summarized in Gee and Bauder [23]. Apart from quantifying the grain size classes, the determination of clay mineralogy can also be considered important as it allows assessment of some characteristics such as the existence of charged sites, which might be considered crucial in natural attenuation [24]. The clay minerals are product of weathering and have marked effects on both chemical and physical properties of the soils. The importance of clays in the soil chemical properties relates to their comparatively large surface area and permanent charge in the surface [25]. Clay mineralogy can be determined from suspension in demineralized water following sample preparation techniques and interpretation of the mixed clay layers based on Moore and Reynolds [26].

Soil organic matter (SOM), or organic carbon (OC) is a mixture of plant and animal residues in different stages of decomposition, substances synthesized microbiologically or chemically from breakdown products, and the bodies of living and dead microorganisms and their decomposing remains [27]. SOM normally ranges from $0.5-5 \%$ in mineral soils and up to $100 \%$ in organic soils (Histosols). Even in very low concentrations, the activity of $\mathrm{OM}$ is so high that it has a pronounced effect on soil chemical reactions [28]. The Walkley-Black method is the generally accepted method for organic carbon determination [29].

\subsubsection{Water samples / eluates}

After collection in the field, water samples should be kept refrigerated and transported to the laboratory. Upon arrival, the samples should be filtered and the measurements to be conducted as soon as possible within $24 \mathrm{~h}$, in or- 
der to minimize the sample changes. At the end of the various extraction techniques the samples are filtered and the final eluate is stored in the fridge until measurement. The storage period should be as short as possible in order to avoid any precipitation and changes in chemistry or reactivity.

$\mathrm{pH}$, redox potential and electrical conductivity in water samples or eluates should be measured after calibrating the respective apparatuses versus known standards. For additional water sample characterization sulfate and chlorides concentrations in the eluates from the extractions and the water samples can also be measured.

\subsection{Total concentrations}

The term total concentration is used for the maximum concentration obtained after the hot plate digestion of one or multiple strong acids on solid samples. Due to the total dissolution, the results give no indication of the species in which heavy metals occur in the soil system.

The measurement of the total concentration of metals in soils/sediments is useful for assessing the degree of contamination and for measuring any change in elemental concentrations over time with respect to leaching to groundwater, surface runoff, erosion, etc. The complete dissolution of the solid phase components requires a rigorous digestion of the powdered sample fraction using a hot mixture of several acids $[10,30]$, which should finally result in a minimum insoluble residue material. With respect to the total concentrations in several studies, Farmer et al. [31], Marguí et al. [32] showed that the finer the powder fraction, the higher is the concentration of the heavy metals released in solution. In a study carried out on chromite ore processing residue wastes [31] the concentration of total $\mathrm{Cr}$ as well as mobile $\mathrm{Cr}(\mathrm{Cr}(\mathrm{VI}))$ in solutions doubled, if the powdered material is $<0.63 \mu \mathrm{m}$.

Total concentrations of major elements such as $\mathrm{Fe}, \mathrm{Ca}$, $\mathrm{Mg}, \mathrm{Al}$, can be measured by means of Atomic Absorption Spectrometry (AAS) while the trace elements such as $\mathrm{Cr}$, $\mathrm{Ni}, \mathrm{Co}, \mathrm{Zn}, \mathrm{Cu}$, can be measured by means of Inductively Coupled Plasma Mass Spectroscopy (ICP-MS), or Optical Emission Spectrometry (ICP-OES) Atomic Emission Spectroscopy (ICP-AES) Speciated Isotope Dilution Mass Spectrometry (SID-MS), Reversed Phase Liquid Chromatorgraphy (HPLC). The selection of the measuring technique will depend highly on the detection limit of the expected concentrations of respective elements. Hill et al. [6] made an extensive summary of all the available detection techniques and possibilities for various sampling types and element speciation.

To evaluate the accuracy of sampling, sample treatment and analysis, is advisable to analyze in duplicate $10 \%$ of samples and to add blank samples to the series. The results from duplicates will indicate whether the analyzed samples are representative especially for the heterogeneity, while the results from the blank samples will indicate whether the generated data are reliable.

\subsection{Extractions}

Using total concentrations to measure element mobility is inappropriate because this approach includes the assumption that all phases have equal control on element mobility. It is known that contaminants can cycle across the sediment (and less soil)-water interface many times. In general a contaminant is not fixed permanently into a soil/sediment particle, and many physical and chemical variables such as weathering, percolation, solubility, speciation, etc, can influence the contaminant mobility as shown by Linge [33]. Measurement of total concentrations is useful for a certain sampling media, but the mobility of heavy metals depends strongly on speciation, binding capacity as well as on the dominant conditions in the site $[32,34]$. Due to these factors, there is an increasing interest in the assessment of the bioavailable metal fraction, the element mobility and the speciation of the trace elements that are mobilized from wastes [35]. However, the determination of speciation is difficult and often impossible. The mobility of a contaminant (especially $\mathrm{Cr}$ ), can be assessed by the determination of the fraction which becomes available under conditions such as acidification, alkalinization, low content of organic carbon. Such determinations might be carried out by simulating similar conditions that could occur in nature with so-called single extractions or by sequential extractions. Such schemes were designed in the 1980s (see for example [36, 37], in order to assess the different conditions for simulating the retention or the release of metals from soils and sediment samples. The idea of a single extraction is that different sampling media are extracted with a reagent that elutes a specific fraction (exchangeable, metal complex release, water soluble) while in a sequential extraction the same sample is successively extracted with several reagents in order to recognize the fraction (i.e. exchangeable, acid extractable, reducible, oxidable and residual) with which the heavy metals associate.

\subsubsection{Single extractions}

Single extractions are inexpensive, simple, effective and fast. They require minimal technical expertise and give an idea on the overall heavy metal availability from the contaminated media [38]. They are more reliable than total concentrations with respect to the mobility of the pollutants. This type of extraction is devoid of sample losses 
due to washing, since there are no subsequent steps as in sequential extraction. The drawbacks of single extractions relate to the operationally defined parameters (i.e. time, ratio, $\mathrm{pH}$ of the extracting agent). More quantity of sample is needed if different types of extractions are carried out and inaccuracies may be introduced by sample heterogeneity (Table 1). It is not always possible to compare the results with certified reference materials due to the large variability of the reagents used in the extractions $[34,39]$. The numerous single extraction methods that have been reported fall into three categories: dilute solutions of strong acids; solutions of weak acids; solutions of strong complexing and reducing agents [34]. In Table 2 some widely used single extractions are shown with the respective references and their operational parameters.

Quantifying the soluble and insoluble fractions of $\mathrm{Cr}$ from the different sampling media is pertinent to the environmental hazards associated especially with: 1. airborne related dust; 2 . colloid and solute movement in the groundwater or absorption by plants and microorganisms as stressed by James et al. [40]. Therefore the quantification of the soluble, exchangeable and crystalline forms of $\mathrm{Cr}(\mathrm{VI})$ (expressed as the total amount of $\mathrm{Cr}(\mathrm{VI})$ in a sampling media), has direct implications for the assessment of $\mathrm{Cr}$ hazards in the environment [40]. This information also helps to minimize expenditure on environmental remediation that would be unnecessary if all $\mathrm{Cr}$ were present as $\mathrm{Cr}(\mathrm{VI})$ [41]. Strong alkaline reagents are recommended for solids in order to minimize undesired $\mathrm{Cr}(\mathrm{III})-\mathrm{Cr}(\mathrm{VI})$ redox reactions during extraction [42]. The carbonate/hydroxide extraction method has been used by James et al. [40], Szulczewski et al. [43], Vitale et al. [41] and Farmer et al. [31], which consider this method as the most effective for the measurement of "total" $\mathrm{Cr}(\mathrm{VI})$ in soils. However the main remark made by Szulczewski et al. [43] is that "not only do such treatment perturb the chemical and the physical properties of the soil-water system, moreover there is no way to verify that all the $\mathrm{Cr}(\mathrm{VI})$ has been extracted". It is important to note that, especially with regard to the carbonate/hydroxide extraction, some dark colors (i.e. varying from light brown to dark brown related to high amounts of organic matter which are mobilized) interfere during the colorimetric measurements (for $\mathrm{Cr}(\mathrm{VI})$ ), artificially increasing the value of the measured $\mathrm{Cr}(\mathrm{VI})$ [42].

\subsubsection{Cascade Leaching Test (CLT)}

Under natural conditions, waste materials are frequently in contact with water (e. g. rain or groundwater). In order to simulate such conditions successive leaching with water is carried out under laboratory conditions. Such a method provides information on the behavior of solid matrix waste in contact with water. To observe the leaching of the heavy metals under long water exposures, the water leaching procedure is repeated three (DIN 38414-S4 [44]) or five times (NEN 7349, [45]; the so called Cascade Leaching Test, CLT). In Tack et al. [48], such extraction is carried out at a constant $\mathrm{pH}$ of 4 to simulate acid rain conditions, while in the NEN 7349 [45] protocol the $\mathrm{pH}$ at the end of the CLT is similar to the natural $\mathrm{pH}$ of the sample due to the impact of the buffering capacity (BC) of the sample. A summary of the leaching parameters is given in Table 3.

These leaching tests allow the determination of the leached amounts of a component, both per fraction, and as the cumulative leached amount. The sum of elements released in three or five extractions fraction removed from this leaching procedure was termed "soluble", while the amount retained in the sediments was termed "insoluble". Since no reference material exists for these leaching procedures, $10 \%$ of the extractions can be carried out in duplicate in order to evaluate the reproducibility of the results. The residue remaining after a specific leaching test can be analyzed by XRD or Scanning Electron Microscopy (SEM), in order to observe the particle changes due to the leaching procedure.

\subsubsection{Sequential extractions}

The use of such extraction is based on the premise that chemical reagents can remove elements or dissolve specific solid phase fractions. In essence sequential extractions use multiple extraction steps with chemical reagents of various strengths, solid/solution ratios, reaction times, temperature, $\mathrm{pH}$ controlling conditions, which are summarized as "operationally defined" parameters [49] in Table 1.

The measurement of operationally defined metal fractions will allow some forecasting of metal release from soils or sediments under certain conditions. It is therefore a valuable tool in the further management of contaminated soils and sediments. Several hybridizations and modifications have been made to the original 5-step sequential extraction procedure of Tessier et al. [36]. On behalf of the European Commission Bureau of Reference (BCR) team, Quevauviller et al. [50] introduced the simplified BCR procedure. This scheme (Table 4) yields information on three metal fractions: 1. the exchangeable fraction (associated with carbonates); 2 . the reducible fraction associated with easily and moderately reducible iron and manganese oxides; 3. oxidable fraction associated with organic matter and sulfide phases; and the residual fraction remaining undissolved after the three steps.

Sequential extraction, when applied in comparative sense, can provide valuable information that highlights the differences in element mobility or reactivity in a particular environmental context. Such information is valuable for 
Table 1. Advantages and drawbacks of the single and sequential extractions.

\begin{tabular}{llll}
\hline \multicolumn{2}{c}{ Single Extractions } & & Sequential Extractions \\
\hline Advantages & Drawbacks & Advantages & Drawbacks \\
\hline \hline More reliable than total concentrations: & Operationally defined: & Valuable information: & Operationally defined: \\
$\rightarrow$ Gives idea of the general availability & $\rightarrow$ Shaking time, ratio, pH. ... & $\rightarrow$ Elemental fractioning & $\rightarrow$ Shaking time, ratio, pH.... \\
& Simple: & More sample needed: & Small quantity of sample: Long: \\
$\rightarrow$ Only one extraction step & $\rightarrow$ Separate extractions & $\rightarrow$ Same sample & $\rightarrow$ Due to consecutive extractions \\
Fast: & Errors: & Errors: \\
$\rightarrow$ Due the simultaneous different & $\rightarrow$ Due to sample heterogeneity & $\rightarrow$ Due to sample heterogeneity \\
extractions & Certified references: & Risk of sample losses: \\
No risk of sample losses: & $\rightarrow$ Not always available & $\rightarrow$ During the extractions and washing \\
$\rightarrow$ Absence of consecutive phase & & Hybridization of schemes: \\
separations and washing steps & & $\rightarrow$ Based on the aim of the study \\
Not all the work is lost: & & Certified references: \\
$\rightarrow$ lf something goes wrong & & $\rightarrow$ Not always available \\
during one extraction & & Problems: \\
& & & $\rightarrow$ Readsorption and redistribution \\
\end{tabular}

Table 2. Summary of single extractions used to infer the release of metals from soils and sediments under different conditions. S/L - Solid Liquid ratio; CRM - Certified Reference Materials; N. R. - Not Reported.

\begin{tabular}{|c|c|c|c|c|c|c|c|c|}
\hline \multirow[t]{2}{*}{ Single Extractions } & \multirow[t]{2}{*}{ Labile fraction } & \multirow[t]{2}{*}{ Concentration } & \multirow[t]{2}{*}{$\mathrm{pH}$} & \multirow[t]{2}{*}{$\mathrm{S} / \mathrm{L}$ ratio } & \multicolumn{2}{|c|}{ Shaking } & \multirow[t]{2}{*}{ CRM } & \multirow[t]{2}{*}{ Reference } \\
\hline & & & & & time (h) & intensity (rpm) & & \\
\hline $\mathrm{CaCl}_{2}$ & $\begin{array}{l}\text { supposed to reflect soil so- } \\
\text { lution }\end{array}$ & $0.01 \mathrm{M}$ & 5 & $1 / 10$ & 3 & 30 & CRM 483 & Quevauviller et al., [50] \\
\hline EDTA & $\begin{array}{l}\text { complexant, supposed to } \\
\text { release metal complexes }\end{array}$ & $0.05 \mathrm{M}$ & 7 & $1 / 10$ & 1 & 30 & CRM 483 & $\begin{array}{l}\text { Quevauviller et al., [50]; Pueyo et } \\
\text { al., [35]. }\end{array}$ \\
\hline $\mathrm{CH}_{3} \mathrm{COOH}$ (acetic acid) & $\begin{array}{l}\text { indicates the effect of acid- } \\
\text { ification }\end{array}$ & $0.43 \mathrm{M}$ & 4.8 & 0.025 & 16 & 30 & CRM 483 & $\begin{array}{l}\text { Quevauviller et al., [50]; Pueyo et } \\
\text { al., [35]. }\end{array}$ \\
\hline Water & $\begin{array}{l}\text { indicates the water soluble } \\
\mathrm{Cr}(\mathrm{VI})\end{array}$ & - & 5.7 & 0.05 & 1 & N.R. & & Vitale et al., [41] \\
\hline $\begin{array}{l}\mathrm{K}_{2} \mathrm{HPO}_{4}(\text { Phosphate } \\
\text { buffer) }\end{array}$ & $\begin{array}{l}\text { soluble }+ \text { exchangeable } \\
\mathrm{Cr}(\mathrm{VI})\end{array}$ & $5 \mathrm{mM}$ & 7 & 0.05 & 1 & N.R. & & Vitale et al., [41] \\
\hline $\mathrm{HCl}$ & equal to the 3-step BCR & $0.5 \mathrm{M}$ & & 0.05 & 1 & N.R. & & Sutherland [34] \\
\hline $\begin{array}{l}\mathrm{Na}_{2} \mathrm{CO}_{3} / \mathrm{NaOH} \text { (Carbon- } \\
\text { ate/Hydroxide) }\end{array}$ & Total Cr(VI) & $0.28 \mathrm{M} / 0.5 \mathrm{M}$ & 11.8 & 0.05 & 1 & N.R. & & James et al., [40]; Vitale et al., [41] \\
\hline $\begin{array}{l}\mathrm{NaOH} \text { sonication (Hydrox- } \\
\text { ide solution) }\end{array}$ & Total Cr(VI) & $0.1 \mathrm{M}$ & 13 & 0.05 & 1 & N.R. & & James et al., [40]; Vitale et al., [41] \\
\hline $\begin{array}{l}\mathrm{NaOH} 95^{\circ} \mathrm{C} \text { (Hydroxide } \\
\text { solution) }\end{array}$ & Total Cr(VI) & $0.1 \mathrm{M}$ & 13 & 0.05 & 1 & N.R. & & James et al., [40]; Vitale et al., [41] \\
\hline
\end{tabular}

predicting the heavy metal mobility, bioavailability and leaching fractions from the different sampling media [51]. However, there has been criticism regarding the application of sequential extraction procedures [49, 52-54]. According to these authors the methods are not entirely specific for the geochemical fraction of the soil and the eluates may also remove metals from other fractions. Major problems may be associated with readsorption phenomena which leads to artificially low concentrations of the heavy metal being released in a specific extraction step, the duration of the experiment, $\mathrm{pH}$ of the leached solution, temperature, particle sizes analyzed, the large number of reagents used as well as the loss of material during ex- periment manipulations since the sample is filtered after each extraction step. Poor recoveries are obtained if the BCR three-step sequential extraction is applied to 100 $\mathrm{mg}$ specimens rather than to $1 \mathrm{~g}$. $\mathrm{pH}$ stability during step 2 and its influence on recoveries is also reported [55]. McLean and Bledsoe [10] stated that no extraction procedure can be universally applicable to all the metals and soils. The most suitable extracting agent for defining the mobile fraction of metals in soils under specific site conditions is the one that simulates most accurately the solution chemistry of the soil. A summary of the advantages and drawbacks of the single and sequential extractions is given in Table 1. Despite its drawbacks, the sequential 
Table 3. Overview of the parameters to perform the Cascade Leaching Test (CLT) according to NEN 7349 [46], NEN 7341 [47], DIN 38414-S4 [44] and modified NEN7349 [46].

\begin{tabular}{|c|c|c|c|c|}
\hline \multirow[t]{2}{*}{ CLT Parameters } & \multirow[t]{2}{*}{ NEN 7349} & NEN 7341 & DIN 38414-S4 & \multirow{2}{*}{$\begin{array}{l}\text { Modified } \\
\text { NEN } 7349 \\
\end{array}$} \\
\hline & & \multicolumn{2}{|l|}{ Tack et al., [48] } & \\
\hline particle size (mm) & powder & powder & $<10$ & $<2$ \\
\hline $\mathrm{S} / \mathrm{L}$ ratio & $1 / 20,40,60,80100$ & $1 / 100$ & $1 / 10$ & $1 / 20,40,60,80,100$ \\
\hline Liquid & water * & HNO3 1M & demineralized water & water * \\
\hline $\mathrm{pH}$ & initial $\mathrm{pH} 4$ & constant $\mathrm{pH} 4$ & N.R. & initial $\mathrm{pH} 4$ \\
\hline Shaking frequency $\left(\mathrm{min}^{-1}\right)$ & 4 & N.R. & N.R. & 4 \\
\hline Shaking device & mechanical shaker & magnetic stirrer & N.R. & horizontal shaker $\left(45^{\circ}\right)$ \\
\hline Duration one step (h) & 23 & 4 & 24 & 12 \\
\hline Subsequent steps & 5 & 1 & 3 & 5 \\
\hline Filtration $(\mu \mathrm{m})$ & 0.45 & 0.45 & 0.45 & 0.45 \\
\hline
\end{tabular}

$\mathrm{S} / \mathrm{L}$ - Solid Liquid ratio; " water is acidified to $\mathrm{pH} 4$ with a diluted solution of HNO3; N.R. - Not Reported

Table 4. Sequential extraction protocols based on Tessier et al., [36] and the Quevauviller et al., [50] schemes.

\begin{tabular}{|c|c|c|c|}
\hline Scheme & Step & Chemical agents and conditions & Fraction extracted \\
\hline \multirow{6}{*}{ Tessier et al., [36] } & Step 1 & $8 \mathrm{ml} \mathrm{MgCl} 2(1 \mathrm{M} ; \mathrm{pH} 7) ; 1 \mathrm{~h}$ agitation & Exchangeable \\
\hline & Step 2 & $8 \mathrm{ml} \mathrm{CH}{ }_{3} \mathrm{COOH}$ acetic acid $(1 \mathrm{M})$ to $\mathrm{pH} 5 ; 5$ hour agitation & Bound to carbonates \\
\hline & Step 3 & $\begin{array}{l}20 \mathrm{ml} \mathrm{NH} \mathrm{N}_{2} \mathrm{OH} . \mathrm{HCl}(0,1 \mathrm{M}) \text { in } \mathrm{HNO}_{3}(0,01 \mathrm{M}) \mathrm{pH} 2 \text {; at } 96 \pm 3^{\circ} \mathrm{C} \\
\text { with occasional agitation until complete dissolution occurs }\end{array}$ & Bound to Fe-Mn Oxides \\
\hline & Step 4 & $\begin{array}{l}3 \mathrm{ml} \mathrm{HNO} \mathrm{HNO}_{3}(0,02 \mathrm{M}) \text { and } 5 \mathrm{ml} \text { of } \mathrm{H}_{2} \mathrm{O}_{2}(30 \%) \text {; the mixture is } \\
\text { heated for } 3 \text { hours up to } 85 \pm 2^{\circ} \mathrm{C} \text { by occasional agitation; }\end{array}$ & Bound to Organic Matter \\
\hline & & $\begin{array}{l}\text { add } 3 \mathrm{ml} \text { of } \mathrm{H}_{2} \mathrm{O}_{2}(30 \%) \text {; the mixture is heated for } 3 \mathrm{~h} \text { with } \\
\text { intermediate agitation; after cooling } 5 \mathrm{ml} \text { of } 3,2 \mathrm{M} \mathrm{NH}_{4} \mathrm{OAc} \\
\text { was added and the sample was diluted up to } 20 \mathrm{ml} \text { and } \\
\text { agitated continuously for } 30 \mathrm{~min} \text {. }\end{array}$ & \\
\hline & Step 5 & $\begin{array}{l}2 \mathrm{ml} \mathrm{HClO}_{4}, 10 \mathrm{ml} \mathrm{HF}_{\text {conc }} \text { mixture; heat gently until half dry } \\
\text { subsequently add } 1 \mathrm{ml} \mathrm{HClO}_{4} \text { conc, } 10 \mathrm{ml} \mathrm{HF} \text { conc mixture; } \\
\text { heated until completely dry; finally add } 1 \mathrm{ml} \mathrm{HClO} 4 \\
\text { and evaporate until the white fumes disappear; } \\
\text { finally redissolve with } 25 \mathrm{ml} \mathrm{HCl}(12 \mathrm{M}) \text { and dilute up to } 25 \mathrm{ml}\end{array}$ & Residual \\
\hline \multirow{4}{*}{ Quevauviller et al., [50] } & Step 1 & $40 \mathrm{ml} \mathrm{CH}{ }_{3} \mathrm{COONH}_{4}(0,11 \mathrm{M} ; \mathrm{pH} 7) ; 16 \mathrm{~h}$ agitation, $22 \pm 5^{\circ} \mathrm{C}$ & Acid Extractable \\
\hline & Step 2 & $40 \mathrm{ml} \mathrm{NH}{ }_{2} \mathrm{OH} . \mathrm{HCl}$ in $0,05 \mathrm{M} \mathrm{HNO}_{3} ; 16 \mathrm{~h}$ agitation; $22 \pm 5^{\circ} \mathrm{C}$ & Reducible \\
\hline & Step 3 & $\begin{array}{l}10 \mathrm{ml} \mathrm{H} \mathrm{O}_{2}(\mathrm{pH} 2-3) \text { heat }\left(85^{\circ} \mathrm{C}\right) ; 1 \mathrm{~h} \text { at } 20^{\circ} \mathrm{C} \text {; } \\
\text { heat at } 85^{\circ} \mathrm{C} 1 \mathrm{~h} \text {; add } 10 \mathrm{ml} \mathrm{H} \mathrm{O}_{2} \text {; heat }\left(85^{\circ} \mathrm{C}\right), 1 \mathrm{~h} \text {; } \\
50 \mathrm{ml} 1 \mathrm{M} \mathrm{NH} 4 \mathrm{OAc}(\mathrm{pH} 2) \text { and shake for } 16 \mathrm{~h}\end{array}$ & Oxidable \\
\hline & Step 4 & $\begin{array}{l}\text { add } 10 \mathrm{ml} \text { aqua regia and evaporate until half dry and let } \\
\text { the sample cool down; then add } 20 \mathrm{ml} 2,5 \mathrm{M} \mathrm{HCl} \text { redissolve } \\
\text { until solution is clear transfer the samples in the } \\
\text { volumetric flasks and dilute to } 50 \mathrm{ml}\end{array}$ & Residue \\
\hline
\end{tabular}

extraction method can provide a valuable tool to distinguish among trace element fractions of different solubility related to mineralogical phases [56].

Most parts of these extraction procedures rely on solution measurements and must be interpreted with caution. However a few studies have used X-ray diffraction (XRD),
Scanning Electron Microscopy with Energy Dispersive X-ray analysis (SEM-EDX), XANES (X-Ray Adsorption Near Edge Structure) to analyze the residue solid phase after extraction with a reagent (see [57-59]). Such techniques allow the solid-phase products to be described after each step. 


\subsection{4. $\mathrm{pH}_{\text {stat }}$ batch tests}

One of the controlling parameters of heavy metal mobility is $\mathrm{pH}$. $\mathrm{pH}_{\text {stat }}$ leaching experiments are batch leaching tests in which automatic titrators are used to keep predefined $\mathrm{pH}$ values static over time. Such experiments can be useful to assess the long-term effects of $\mathrm{pH}$ variation with regard to the leaching characteristics of the heavy metals [60]. Different acid or alkaline solutions can be used during the leaching experiment in order to study the potential release of the heavy metals under these conditions. These tests estimate the mobility of contaminants by simulating changes that might occur in the natural environment (due to acid rain for example) in time with respect to $\mathrm{pH}$ [61]. Moreover, the amount of acid or base added to the suspension to keep the $\mathrm{pH}$ value at the predefined set-point gives a quantitative estimation of the Acid Neutralizing Capacity (ANC) or Basic Neutralizing Capacity (BNC) of the sample [61-63]. The parameters and the discussion addressing the $\mathrm{Cr}$ speciation and mobility are addressed elsewhere [64].

\subsubsection{Column test}

The principle of the column test consists in simulating the leaching of contaminants from granular materials (soils/sediments) using solutions at various concentrations. Column leaching tests are percolation tests in which a solution (leachate) passes through a column that contains soil/sediment material without agitation [45]. Column tests can be performed with undisturbed soil/sediment material (the original structure is preserved) or on disturbed samples (the structure is not preserved, rather, the sample is packed into the column). The retention time of the solution varies depending on the strength of its interactions with the granular material in the column, the ratio/composition of solvent(s) used, and the flow rate of the mobile phase.

\subsection{Speciation}

Speciation is a term widely used in chemistry that requires a good definition in order to describe its context. "Chemical species" is the specific form of an element defined as isotopic composition, electronic or oxidation state, and/or complex or molecular structure (i.e. $\mathrm{Cr}(\mathrm{III})$ as $\mathrm{Cr}_{2} \mathrm{O}_{3}$ while $\mathrm{Cr}(\mathrm{VI})$ as $\left.\mathrm{CrO}_{4}^{2-}\right)[51,65]$. "Speciation" of an element is defined as the distribution of an element amongst defined species in a system, while the term "speciation analysis" is used to identify and/or measure the quantities of one or more individual species in a sample. Therefore, speciation is a key factor in distinguishing between different signatures (i.e. background and anthropogenic). Moreover, by quantifying the different chemical species, accurate pre- diction for to heavy metal mobilization, bioavailability, as well as leaching rates of the toxic forms from the wastes can be made $[51,65,66]$. Speciation determines the mobility, bioavailability and the toxicity of a metal and that metal speciation depends highly on the site-specific seasonal and spatial variation existing in a particular water, sediment or soil system [67].

It is often impossible to determine the different chemical species in a system, due to the complexity of such analysis; in this instance fractionation, defined as the process of classification of an analyte according to physical and chemical properties may be a useful approach [51].

Kotas J., Stasicka Z., [68] made a summary of all the techniques available for the $\mathrm{Cr}$ speciation in solid matrix samples, while Hill et al. [6] indicated a list of main elements and the relative techniques that can be used to measure them in various sample media. Below will be illustrated the various species of chromium and some techniques for illustration. $\mathrm{Cr}(\mathrm{VI})$ species can be quantitatively assessed by colorimetry in the liquid samples (i.e. water, eluates, extractions) and by mineralogy (Figure 1) in the solid matrix samples (i.e. soils, sediments, dusts).

\subsubsection{Colorimetry}

The quantification of the $\mathrm{Cr}(\mathrm{VI})$ in solution is carried out by applying the colorimetric diphenylcarbazide (DCB) method [69]. Diphenylcarbazide at $\mathrm{pH} 2 \pm 0.5$ gives a red violet colour in the presence of $\mathrm{Cr}(\mathrm{VI})$. Five minutes after the reaction takes place, the absorbance of the sample is measured with an UV-VIS Spectrophotometer 635, at $540 \mathrm{~nm}$ employing calibration standards (prepared from $10 \mathrm{mg} / \mathrm{L} \mathrm{K}_{2} \mathrm{Cr}_{2} \mathrm{O}_{7}$ ) in the range $0.05-2.0 \mathrm{mg} / \mathrm{L}$. To minimize changes in chromium speciation, analyses should be carried out within 24 hours. In the eluates it was assumed that all $\mathrm{Cr}$ leached was composed of $\mathrm{Cr}(\mathrm{III})_{\text {sol. }}+\mathrm{Cr}(\mathrm{VI})_{\text {sol. }}$. If no red-violet colour was formed in the leachates during colorimetry reaction but $\mathrm{Cr}$ could be measured by AAS this was assumed to correspond to total soluble $\mathrm{Cr}$ (i.e. $\mathrm{Cr}(\mathrm{III})$ ). If more $\mathrm{Cr}$ was detected by AAS than by colorimetry, the surplus was assumed to correspond to soluble $\mathrm{Cr}(\mathrm{III})$. To summarize, $\mathrm{Cr}(\mathrm{III})$ is calculated as follows:

$$
\mathrm{Cr}(\mathrm{III})_{\text {sol. }}=\mathrm{Cr}_{\text {tot.sol. }}-\mathrm{Cr}(\mathrm{VI})_{\text {sol. }}
$$

The dissolution of organic matter might overestimate the soluble $\mathrm{Cr}(\mathrm{VI})$ in solution. Similar discrepancies have been reported in sites highly contaminated sites by COPR in New Jersey [70], Glasgow [31, 71, 72] and Pettine and Capri [42]. According to the latter authors the dissolution of humic matter (HM), especially in alkaline environments (digestion [41], see Table 2) might be the cause of the overestimation. Therefore, interpretation of the results must be carried out with caution especially when the OC 
content is very high. In the case of solid matrix samples, additional mineralogical analysis must be carried out.

\subsubsection{Mineralogy}

Qualitative analysis (identification) of mineral phases by $X$ Ray Diffraction (XRD) is usually a straightforward procedure based on searching and matching XRD reference patterns with those of unknown materials. Even when the most sophisticated search matches are employed, additional geochemical information is useful in the mineralogical identification. Moreover, Scanning Electron Microscope (SEM) and Energy Dispersive X-ray analysis (EDX) can provide morphological and compositional information that is phase specific and hence supplement data obtained by XRD. Quantitative analysis by XRD is difficult to achieve, especially when the samples contain complex mixtures of phases, as is often the case with highly contaminated sites or from waste materials [73]. Thus the complexity of many such mixtures and the resulting XRD patterns means that quantitative methods based on the measurement of single/several resolved peaks are often not feasible, but the trend (when possible) can be ameliorated by sample pre-treatment. However, a combination of geochemistry, XRD, SEM and EDX often gives consistent data on the composition of different sampling media.

\section{$X R D$}

X-ray scattering techniques are a family of nondestructive analytical techniques which reveal information about the crystallographic structure, chemical composition, and physical properties of materials and thin films. These techniques are based on observing the scattered intensity of an X-ray beam hitting a sample as a function of incident and scattered angle, polarization, and wavelength or energy. XRD can be carried out for mineralogical characterization of soils, sediments, wastes, dust, and insoluble residue after 4 -acid digestion as well as for the residues from different extractions. The samples for XRD analysis can be oven dried, ground in a mortar and then analyzed without any additional treatment. In the case of residues from digestions or extraction, when the quantities are rather small, the grains can be placed on a glass slide and fixed with silica gel, while in the case of soils/sediments, concentrated fractions of the sample should be prepared when possible. Operational conditions are highly dependent on the element to be measured (scanning angle) and the accuracy required (step size \& counting). Phase identification of the crystalline phases is made with reference to patterns from Mineral Powder Diffraction Files (1986) of the International Center for the Diffraction Data. Moreover, it is important to stress that XRD allows the identification of crystalline phases that make up more then $1-2 \%$ of the sample [74]. Consequently minor constituents and amorphous phases can hardly be detected by this method. Therefore if soil or sediment samples are analyzed, interference by the soil matrix that accounts for most of the sample (i.e. quartz, calcite) hampers the identification of waste materials from various industrial process. In Figure 2, examples of pure crystalline XRD patterns of $\mathrm{Cr}_{2} \mathrm{O}_{3}$ and $\mathrm{K}_{2} \mathrm{Cr}_{2} \mathrm{O}_{7}$ are given [75]. Examples of $\mathrm{XRD}$ chromium contaminated samples are reported in different publications from $[64,76]$.
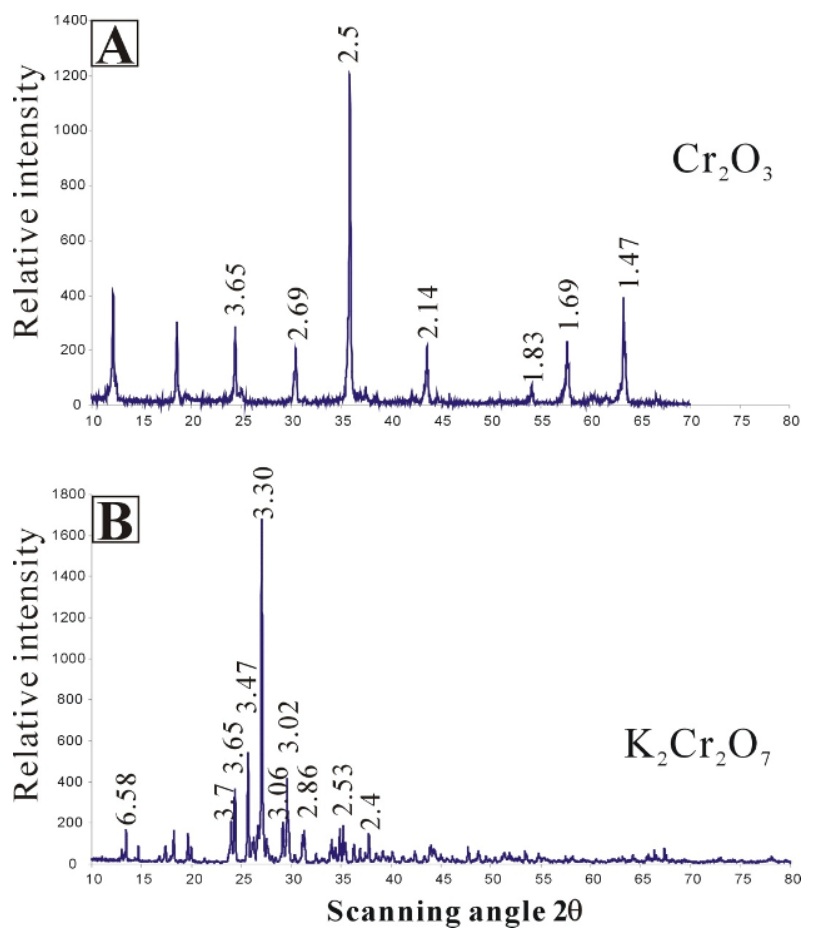

Figure 2. XRD patterns of the pure crystalline phases $\mathrm{A}$. chromite $\mathrm{Cr}_{2} \mathrm{O}_{3}$ (trivalent $\mathrm{Cr}$ ); B. potassium dichromate $\mathrm{K}_{2} \mathrm{Cr}_{2} \mathrm{O}$ 7 (hexavalent Cr) from Shtiza (2007).

\section{SEM-EDX}

The Scanning Electron Microscope (SEM) permits the observation and characterization of heterogeneous organic and inorganic materials on a nanometer $(\mathrm{nm})$ and micrometer $(\mu \mathrm{m})$ scale [77]. This technique consists in collecting images due to scanning with a high energy beam of electrons. The electrons interact with the atoms that make up the sample producing signals that contain information about the sample's surface topography, texture, composition and other properties such as the electrical conductivity.

To reduce their charging during scanning, the samples should be sputter-coated with a conductive layer of Carbon (C) or Gold (Au). After observation of morphological 
characteristics by SEM, the elemental composition of specific phases can be determined by Energy Dispersive $X$ ray (EDX). Apart from the relative contents of the different components, nor SEM nor EDX gives no information on element speciation.

\subsubsection{XANES}

Synchrotron-based technique of X-ray absorption spectroscopy is a non-destructive method which enables the determination of valence and speciation of elements present in solid or liquid samples at different concentrations. Detailed X-ray adsorption near edge structure (XANES) studies on transition metal complexes have demonstrated the sensitivity of $X$-ray adsorption versus edge and (pre)edge features for different species $(\mathrm{Cr}, \mathrm{V}, \mathrm{Ti}$ etc. ...) as indicated by Farges et al. [78]; Szulczewski et al. [43]; Zachara et al. [79]. The presence of the (pre)edge features in the XANES scans indicates that a certain species (e.g $\mathrm{Cr}(\mathrm{VI}))$ is present in the analyzed sample, while the edge indicates that the element (e.g. chromium) is present. Thus, by using the XANES technique is possible to have fast information on the presence and the quantities of a certain element in the analyzed samples.

Data from modern techniques such as XAS (X-ray Absorption Spectroscopy) that give information on the molecular scale of a soil/sediment should be used in conjunction with leaching techniques, but they are expensive and can only be conducted in specialized institutes such as the European Synchrotron Radiation Facility.

\subsubsection{Geochemical modeling}

Several equilibrium thermodynamic computer programs are available for modeling soil solution and solid phase chemistry by providing information on the thermodynamic possibility of certain reactions. As summarized by McLean and Bledsoe [10] these models are used to: 1. calculate the distribution of the free metal ions and metal ligand complexes in a soil solution; 2 . predict the fate of the metals added to soil by providing a list of the precipitation and absorption reactions likely to control the solution concentration of metals; 3 . provide a method to evaluate the impact of changing one or more soil solution parameters (i.e. the $\mathrm{pH}$, redox, inorganic and organic ligand concentration, or metal concentration) on the adsorption or precipitation behavior of the metal(s) of interest. In addition to the calculation of the equilibrium speciation of the chemical elements in the soil solution and precipitation/dissolution reactions, models such as Geochem [80], MINTEQA 2 [81, 82], PHREEQ C [83], ORCHESTRA [84], Visual MINTEQ 2.4 [85], can provide information on cation exchange reactions and metal ion absorption. However it must be stressed that these models are equilibrium models and as such do not take account of the reaction kinetics. The limitations of these models are also related to the thermodynamic database available for the calculations.

\subsection{Reproducibility of the data and reference materials}

Reproducibility of the results is a key issue in environmental studies, especially if it is desired to compare results for soils from different areas, which might have been sampled, treated and analyzed by different people and with different methods [86]. Fortunati and Pasturenzi [7] stated that the error arising from sampling on location is typically larger than that linked to the preparation, manipulation and analysis of the sample. Wagner et al. [87] stated that it is difficult to guarantee that later investigation will meet exactly the same conditions as in previous studies, due to spatial and temporal variability of samples in the field. OECD principles of GLP (Good Laboratory Practice) and compliance monitoring can be found in the documents prepared by $\mathrm{OECD}^{1}$. In chemical laboratories there are in place standard quality assurance (QA) and quality control (QC) procedures which represent the administrative and technical steps undertaken to ensure that reliable data are produced with specified precision and accuracy [88]. Apart from several replicates from the same sampling media, there is a considerable interest in the use of certified reference materials (CRMs) for environmental analysis. A CRM is a reference material with one or more properties which are certified by a technically valid procedure, and which is accompanied by a traceable certificate or other documentation issued by a certifying body [30]. The utility of using CRMs lies in the fact that comparison of results obtained by different analytical methods can be achieved by comparing the values with known materials. The increased requirement for assessment of the bioavailable metal fraction as well as of the mobility of heavy metals which could contaminate soils, sediments and groundwater explains the development in the last decades of a large number of analytical approaches (i.e. single or cascade leaching tests, sequential extractions, $\mathrm{pH}_{\text {stat }}$ batch tests, etc), in order to develop realistic risk assessment models Fairbrother et al. [88]. The large number of methods proposed by Tessier et al. [36], Kerstner and Förstner [37], James et al. [40], La Force and Fendorf [57], Sutherland [34], van Herreweghe et al. [64] and Dold [59] resulted in diversity in the procedures applied, which make the comparison of results extremely difficult. The final

\footnotetext{
1 http://www.oecd.org
} 


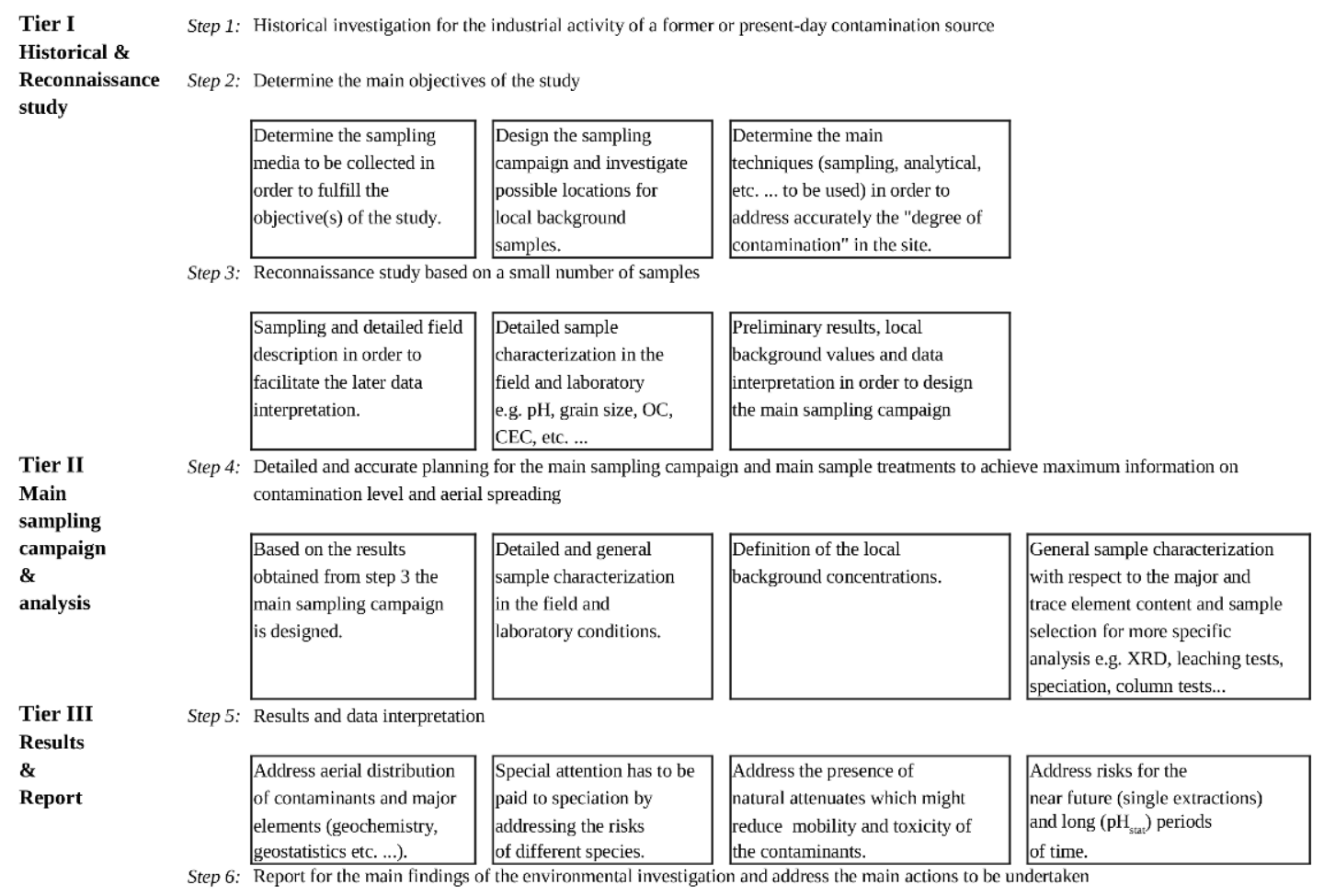

Figure 3. Flowchart of the main steps necessary to perform an environmental investigation of a contaminated site from the industrial activity.

outcome in earlier publications is difficult to assess, due to the lack of certified reference materials for data comparison and the adaptations made during the respective studies. For this reason, the former European Commission Bureau of Reference (BCR), now known as Standard, Measurements and the Testing Program of the European Commission, in an attempt to standardize the procedures and compare the results, has introduced several extraction procedures associated with certified reference materials (CRMs) [51]. Reference materials exist for EDTA, calcium chloride, acetic acid (CRM 483 and 484) and sequential extraction (CRM 601 and BCR 701) methods. The use of the BCR during the tests will provide more reliable data that can be compared with data published in literature or data generated by other laboratories.

Recently a speciated Standard Reference Material (SRM2701) has been prepared by NIST (US National Institute of Standards and Technology) and assigned certified values for Hexavalent Chromium in Contaminated Soil High Level, while the Low Level SRM-2700 is in preparation Nagourney et al. [89]. The source material for the new SRM was collected from a waste site in Hudson County, N.J. After milling, blending, and sterilizing, sci- entists analyzed the samples for hexavalent chromium using several EPA-approved methods designed to minimize and compensate for the chameleon-like chemical properties of chromium. The contaminated soil SRM-2701 has certified values for hexavalent chromium, total chromium, iron and manganese as well as reference values for other elements of environmental interest including aluminum, calcium, magnesium, nickel, silicon, sulfur, titanium and vanadium. Therefore it is vital that a sufficiently detailed description of the analytical procedure is provided and strictly followed, if harmonized results are to be obtained.

\section{Discussion}

The sources of heavy metals in the environment are mainly geogenice and anthropogenic in origin. Heavy metals from solid wastes generated through the mining and processing of mineral ores, as well as from waste generated from daily life, account for a considerable amount of the total released through anthropogenice activities. Improper disposal of waste(s) can cause wind and water erosion, which can ultimately result in the transportation of contaminants. 
Depending on the mobility of contaminants, leakage from waste piles could then pollute nearby groundwater systems and surface streams. These processes, as well as additional questions related to the specific impacts of metals on the environment and on human health, reflect the need to establish ready and accessible metal-specific tools and data sets in order to make informed, science-based decisions. Since the methods and models used to evaluate hazards, set priorities, establish environmental criteria, and assess risks, are currently developed and used in different jurisdictions, such as the European Union, the United States, Canada and so on, this makes the final outcome of these investigations very difficult to compare $[1,2]$. Over the last few decades, a large number of techniques, such as, total trace element characterization, single extractions, sequential extractions, $\mathrm{pH}$ - dependent leaching tests, column tests, etc., have been used to characterize different sampling media, such as soils, sediments, dust particles and, wastes. These techniques were developed to characterize the mobility of contaminants and their impact on the environment, taking into account that the leaching behaviors of specific constituents are a function of key controlling factors which are common to many materials such as $\mathrm{pH}$, organic matter, dissolved organic matter (DOM), redox and salt load $[90,91]$. In environmental studies, the release and readsorption of trace elements is important for establishing the mobile fraction as well as speciation under various chemical conditions. While the release of trace elements is important from the ecotoxicity point of view, their retention is relevant in order to design specific physico-chemical treatments that can bind them to the immobile fraction of the soil/sediment particle [91]. Contaminant remobilization occurs when altered ambient conditions induce changes in retention capacity of the soils/sediments particles. Choosing the most appropriate analytical methodology requires an understanding of how the contaminant binds to the soils/sediment and the conditions under which the contaminant will be released. As indicated in the previous sections, the results obtained upon application of operationally-defined speciation protocols largely depend on conditions (reagents and their concentrations, treatment times, temperature, etc.), making comparison between partitioning patterns obtained using different schemes is difficult. The accuracy of sequential extraction methods is much more difficult to estimate than that of a total metal determination due to the many extraction steps involved. Moreover, mimicking field conditions in the laboratory is a difficult task since the methods are operationally defined, whereas the testing techniques are developed to quantify and understand the contaminant mobility under specific leaching or testing conditions and to predict changes over time by using chemical models $[63,64]$. The large variety of environmental problems, a direct legacy of industrial expansion, has to deal also with the large number of techniques used to achieve the most relevant information with respect to risks related to deposition of wastes and different discharge pathways. The total concentration digestion yields data on the total amount of major and trace elements without providing any information on the binding processes or availability of the investigated elements, while the single or sequential extraction will depend highly greatly on the information that needs to be collected. Single extractions are generally considered to be fast methods that provide insights into the sediment/soil leaching behavior for short periods of time. Generally, sequential extractions leaching techniques that last for days are criticized for being time consuming, readsorption process between subsequent steps, and require qualified personnel $[49,55,56]$, however they do provide comprehensive information on the origin, occurrence, biological and physico-chemical availability, mobilization and transport of trace elements [91]. They have also shown to be convenient for determining the trace element association with the main accumulative phases in soils and sediments, since the selected extractants are environmentally meaningful, and also fors distinguishing between geogene and anthropogene trace element originss $[36,91]$. Despite the aforementioned drawbacks, these methods have been extensively used in recent years, especially since the introduction of certified reference materials with certified amounts of extractable trace elements, the use of which can reduce uncertainty and increase the validity and harmonization of the applied techniques. Since the majority of environmental studies have been conducted on soils and sediments, and, very few studies have been conducted on dust particles, fly ash, or solid waste incineration, the use of , these certified reference materials should be expanded in order to broaden the scope of these types of studies and the overall application on these leaching techniques. A threetiered approach consisting of: 1. historical and reconnaissance study; 2 . main sampling campaign and analysis; and 3. results and reports, is proposed to address the possible pollution/contamination caused by industrial activities (Figure 3). This protocol can be used when the deposition, discharge and transportation of pollutants has occurred for some time, and can recommends various steps be followed in order to confine the aerial extension of contamination and quantify the contamination/ pollution levels (Figure 3). Moreover, special attention should be given to the deduction of local background concentrations, chemical speciations, predictions for changes in both the short and long term, and any implications for natural attenuation processes $[65,76]$. Not all the collected samples 
should be analyzed in detail from the beginning. After general sample characterization in the field and laboratory, geochemical analyses can provide an overview with respect to the distribution of the contaminants based on total concentrations. Specific extractions, mineralogical determinations, and additional treatments can be carried out on particular samples only. This is the case for spectroscopic techniques such as XANES and XAS, which are less accessible, more expensive, and sometimes may not be sensitive enough for background samples [33]. Because uncertainty resulting from sampling and sample pretreatment can have a major impact on the final results even when the most sophisticated techniques are applied [6, 9], accurate and well described sampling, sample pretreatment and application of standard analytical protocols are crucial in obtaining reliable results $[17,86,87]$. Uncertainty associated with the analytical results is an issue of major interest for the whole analytical community. A major effort has been made to improve the detection limits of many analytical techniques in order to decrease uncertainty. Since heterogeneity and sampling techniques have such an important impact on the final results, fast, cost effective, and reliable screening methods that detect multiple contaminants especially in mixed polluted sites should be developed [90]. On-site measurements cannot by any means substitute for laboratory measurements, but can give a good preliminary estimate of general concentrations.

\section{Conclusions}

In conclusion, it can be stated that after an accurate sampling campaign [4] appropriate sample pre-treatment and the selection of relevant techniques to obtain information on the speciation, mobilization, bioavailability of the contaminants in the environment are required. In order to obtain relevant and reliable results there is a need to use recognized methods and techniques always keeping in mind that project costs must stay within the budget.

The key steps to be remembered and applied during sample pre-treatment and selection of relevant techniques and tools identified by this literature review are the following:

1. Strict adherence tothe standard operational procedures (SOP) for sample pre-treatment in order to prepare a representative and homogeneous sample for analysis, since this phase has been identified as very crucial for generation of reliable results;

2. Accurate selection of the methods to be used in order to address the main issues based on the scope of the project;
3. Use of recognized certified/standard reference materials in order to generate reliable data;

4. Preparation of a preliminary report specifing the samples that will need additional analysis and the rationale;

5. Documentation of any deviation from the SOP and the rationale for the deviation;

6. Preparation of the final draft of the report, including assessment as to whether the initial scope of the project has been fulfilled.

\section{References}

[1] Ferguson C.C., Assessing risks from contaminated sites: Policy and Practice in 16 European countries. Land Contam. Recl., 1999, 7, 33-54

[2] International Council on Mining \& Metals (ICMM), Metals Environmental Risk Assessment Guidance MERAG, International Council on Mining \& Metals, UK, 2007, 1-80.

[3] Nortcliff S., Sampling and pre-treatment and some observations from the United Kingdom. Science of. Total Environment, 2001, 264, 163-168

[4] Shtiza A., Tashko A., Appropriate sampling strategy and analytical methodology to address contamination by industry: Part 1 Conceptual model of a sampling design and sampling types. Central European Journal of Geosciences., 2009, 1, 193-206

[5] USEPA, Guidance of choosing a sampling design for environmental data collection. For use in developing a quality assurance project plan EPA QA/G-5S. EPA/240/R-02/005. 2002, 1-178

[6] Hill S.J., Arowolo T.A., Butler O.T., Chenery S.R.N., Cook J.M., Cresser M.S., Miles D.L., Atomic spectrometry update: Environmental analysis. J. Anal. Atom. Spectrom., 2002, 17: 284-317

[7] Fortunati G.U., Pasturenzi M., Quality in soil sampling. Quim. Anal., 1994, 13, 5-20

[8] Swiss Agency for the Environment, Forests and Landscape (SAFEL), Sampling and sample pre-treatment for soil pollutant monitoring. Swiss Agency for the Environment, Forests and Landscape, Berne 2003, 1104

[9] Narizzano R., Risso F., Innocenti R., Mollica V., Tortarolo B., Soil subsampling in environmental sciences: the role of granulometry. J. Environ. Monit., 2008, 10, 993-997

[10] McLean J.E., Bledsoe B.E., Behavior of metals in soils. EPA/540/S-92/018, 1992, 1-25 
[11] Kersten M., Förstner U., Effect of sample pretreatment on the reliability of solid speciation data of heavy metals - implications for the study of early diagenetic processes. Mar. Chem., 1987, 22, 299-312

[12] Zhang S., Wang S., Shan X., Effect of sample pretreatment upon the metal speciation in sediments by a sequential extraction procedure. Chemical Speciation and Bioavailability, 2001, 13, 69-74

[13] Worsfold P., Gimbert L., Mankasingh U., Omaka O., Hanrahan G., Gardolinski P., Haygarth P., Turner B., Keith-Roach M., McKelvie I., Sampling, sample treatment and quality assurance issues for the determination of phosphorus species in natural waters and soils. Talanta, 2005, 66, 273-293

[14] Turner B., Newman S., Cheesman A., Ramesh R., Sample pre-treatment and phosphorus speciation in wetland soils. Soil Sci. Soc. America J., 2008, 71, 1538-1546

[15] Prietzel J., Tyufekchieva N., Eusterhues K., KögelKnabner I., Thieme J., Paterson D., McNulty I., de Jonge M., Eichert D., Salomé M., Anoxic versus oxic sample pre-treatment: Effects on the speciation of sulfur and iron in well-aerated and wetland soils as assessed by X-ray absorption near-edge spectroscopy (XANES). Geoderma, 2009, 153, 318-330

[16] Paul S., Martinson G., Veldkamp E. Flessa H., Sample pre-treatment affects the distribution of organic carbon in aggregates of tropical grassland soils. Soil Sci. Soc. America J., 2008, 72, 500-506

[17] Wagner G., Desaules A., Muntau H., Theocharopoulos S., Quevauviller Ph., Harmonization and quality assurance in pre-analytical steps of soil contamination studies - conclusions and recommendations of the CEEM Soil project. Science of Total Environment, 2001, 264, 103-117

[18] Food and Agriculture Organization (FAO), Guideline for soil description. Food and Agriculture Organization of the United Nations, Rome, Italy, 2006

[19] Munsell Revised Standard Soil Color Charts. Eijkelkamp Agri-Research Equipment, 1997

[20] Buck R.P., Rondinini S., Covington A.K., Baucke F.G.K., Brett C.M.A., Camões M.F., Milton M.J.T., Mussini T., et al., Measurement of ph. Definition, standards and procedures. Pure and Applied Chemistry, 2002, 74, 2169-2200

[21] SSSA, Glossary of Soil Science Terms, Soil Science Society of America, USA, 1987

[22] van Reeuwijk L.P., Procedures for soil analysis, $3^{\text {rd }}$ ed Wageningen, World Soil Information (ISRIC), the Netherlands, 1992

[23] Gee G.W., Bauder J.W., Particle size analysis. In: Klute A. (Ed.), Methods of soils analysis. Part 1.
Physical and Mineralogical methods. American Society of Agronomy and Soil Science Society, Wisconsin, USA, 1986, 383-411

[24] McLeod N., Chemical immobilization of chromium wastes using modified smectite clays (e-clays). Environ.Geochem. Hlth., 2001, 23, 273-279

[25] Alloway B.J., (Ed.) Heavy metals in soils. Blackie Academic Professional, 1995, 1-10

[26] Moore D.M., Reynolds R.C., (Eds.) X-Ray Diffraction and Identification and Analysis of Clay Minerals. New York: Oxford Univ Press. 1989, 180-271

[27] Schnitzer M., Khan S.U., Chemistry of soil organic matter. In: Sparks D. (Ed.) Environmental soil chemistry. Academic Press, San Diego C.A., 2003, 75-113

[28] Sparks D., (Ed.) Environmental soil chemistry. Academic Press, San Diego C.A., 2003, 1-42

[29] Allison L.E., Organic Carbon, Walkley-Black method. In: Black C.A., (Ed.) Methods of Soil Analysis, Part 2. American Society of Agronomy. Madison, WI., 1965, 1367-1378

[30] Vandecasteele C., Block C.B., Modern Methods for Trace Element Determination. John Wiley \& Sons, Chichester, 1997, 10-72

[31] Farmer J.G., Graham M.C., Thomas R.P., LiconaManzur C., Paterson. E., Campbell C.D., Geelhoed J.S., Lumsdon D.G., et al., Assessment and modelling of the environmental chemistry and potential for remediative treatment of chromium contaminated land. Environ. Geochem. Hlth., 1999, 21, 331-337

[32] Marguí E., Salvadó V., Queralt I., Hidalgo M., Comparison of three-stage sequential extraction and toxicity characteristic leaching tests to evaluate metal mobility in mining wastes. Anal. Chim. Acta., 2004, 524, 151-159

[33] Linge K.L., Methods for investigating trace element binding in sediments. Critic. Review in Environment Science and Technology, 2008, 38, 165-196

[34] Sutherland R.A., Comparison between non-residual $\mathrm{Al}, \mathrm{Co}, \mathrm{Cu}, \mathrm{Fe}, \mathrm{Mn}, \mathrm{Ni}, \mathrm{Pb}$ and $\mathrm{Zn}$ released by a three-step sequential extraction procedure and a dilute hydrochloric acid leach for soil and road deposited sediment. Appl. Geochem., 2002, 17, 353-365

[35] Pueyo M., Rauret G., Bacon J.R., Gomez A., Muntau H., Quevauviller Ph., López-Sánchez J.F., A new organic-rich reference material certified for its EDTAand acetic acid-extractable contents of $\mathrm{Cd}, \mathrm{Cr}, \mathrm{Cu}, \mathrm{Ni}$, $\mathrm{Pb}$ and $\mathrm{Zn}$, following collaboratively tested and harmonized procedures. J. Environ. Qual., 2001, 3, 238242

[36] Tessier A., Campbell P.G.C., Bisson M., Sequential extraction procedure for the speciation of particulate trace metals. Anal. Chem., 1979, 51/7, 844-851 
[37] Kersten M., Förstner U., Chemical fractionation of heavy metals in anoxic estuarine and coastal sediments. Wat. Sci. Technol., 1986, 18, 121-130

[38] Ure A.M., Single extraction schemes for soil analysis and related applications. Sci. Tot. Environ., 1996. 178, 3-10

[39] Tack F.M.G., Vossius H.A.H., Verloo M.G., A comparison between sediment metal fractions, obtained from sequential extraction and estimated from single extractions. Internat. J. Environ. Anal. Chem., 1996, 63, 61-66

[40] James B.R., Petura J.C., Vitale R.J., Mussoline G.R., Hexavalent chromium extraction from soils: A comparison of five methods. Environ. Sci. Technol., 1995, 29: $2377-2381$

[41] Vitale R., Mussoline G., Rinehimer K., Petura J., James B., Extraction of sparingly soluble chromate from soils: evaluation of methods and Eh-pH effects. Environ. Sci. Technol., 1997, 31, 390-394

[42] Pettine M., Capri S., Removal of humic matter interference in the determination of $\mathrm{Cr}(\mathrm{VI})$ in soil extracts by the diphenylcarbazide method. Anal. Chim. Acta., 2005, 540, 239-246

[43] Szulczewski M.D., Helmke P.A., Bleam W.F., Comparision of XANES analysis and extractions to determine chromium speciation in contaminated soils. Environ. Sci. Technol., 1997, 31, 2954-2959

[44] DIN 38414 S4 German Standard methods for the examination of water, waste water and sludge; group $\mathrm{S}$ (sludge and sediments); determination of leachability by water (S4)

[45] NEN 7343., Leaching characteristics of solid earthy and stony building and waste materials. Leaching tests. Determination of inorganic components from granular materials with the column test. Nederlands Normalisatie-Instituut (NEN). $1^{\text {st }}$ edition, February 1995, Delft, 10

[46] NEN 7349, Leaching characteristics of solid earthy and stone building and waste materials. Leaching tests. Determination of the inorganic components from granular materials with the cascade test. Nederlands Normalisatie-Instituut (NEN). $1^{\text {st }}$ edition, February 1995, Delft, 11.

[47] NEN 7341, Leaching characteristics of soil, construction materials and wastes. Leaching tests determination of the avail-ability of inorganic constituents for leaching from construction materials and waste materials. Dutch Standardization Institute, 1994, Delft.

[48] Tack F.M.G., Singh S.P., Verloo M.G., Leaching behavior of $\mathrm{Cd}, \mathrm{Cu}, \mathrm{Pb}$ and $\mathrm{Zn}$ in surface soils derived from dredged sediments. Environ. Poll., 1999, 106, 107-114
[49] Miller W.P., Martens D.C., Zelazny L.W., Effect of sequence on extraction of trace metals from soils. Soil Sci. Soc., 1986, 46, 13-22

[50] Quevauviller Ph., Rauret G., Ure., Bacon J., Muntau $\mathrm{H}$., The certification of the extractable contents (mass fraction) of $\mathrm{Cd}, \mathrm{Cr}, \mathrm{Cu}, \mathrm{Ni}, \mathrm{Pb}$ and $\mathrm{Zn}$ in freshwater sediment following a sequential extraction procedure BCR-701. European Commission, BCR information on reference materials. EUR 17127 En. 1997, 71-73

[51] Templeton D.M., Ariese F., Cornelis R., Danielsson L-G., Muntau H., van Leeuwen H.P., Lobinski R., Guidelines for terms related to chemical speciation and fractionation of elements. Definitions, structural aspects and methodological approaches. Pure Appl. Chem., 2000, 72, 1453-1470

[52] Tipping E., Hetherington N.B., Hilton J., Artifacts in use of selective chemical extraction to determine distribution of metals between oxides of manganese and iron. Anal. Chem., 1985, 57, 1944-1946

[53] Calvet R., Bourgeois S., Msaky J.J. Some experiments on extraction of heavy metals present in soil. Intern. J. Anal. Chem., 1990, 39, 31-45

[54] Sahuquillo A., López-Sánchez J.F., Rubio R., Gauret G., Thomas R.P., Davidson C.M., Ure A.M., Use of a certified reference material for extractable trace metals to assess sources of uncertainty in the BCR threestage extraction procedure. Anal., Chim. Acta., 1999, 382, 317-327

[55] Ciceri E., Giussani B., Pozzi A., Recchia S., Problems in the application of the three-step BCR sequential extraction to low amounts of sediments: an alternative validated route. Talanta, 2008, 76, 621-626

[56] Hlavay J., Prohaska T., Weisz M., Wenzel W., Stingeder G., Detemination of trace elements bound to soils and sediment fractions. Pure Appl. Chem., 2004, 76/2, 415-442

[57] La Force M.J., Fendorf S., Solid-phase iron characterization during common selective sequential extractions. Soil Science Society of America Journal, 2000, 64, 1608-1615

[58] Scheinost A.L., Kretzschmar R., Pfister S., Combining selective sequential extractions, x-ray absorption spectryscopy, and principal component analysis for quantitative zinc speciation in soil. Environ. Sci. Technol., 2002, 36, 5021-5028

[59] Dold B., Speciation of the most soluble phases in a sequential extraction procedure adapted for geochemical studies of copper mine waste. J. Geochem. Explor., 2003, 80, 55-68

[60] Forster V., Heasman L., Kibblewhite M., Quality assurance in the analysis of soil from land contamination. Thomas Telford Publishing, London, UK, 1998, 
901-902

[61] Paschke A., Wennrich R., Morgenstern P., Comparison of $24 \mathrm{~h}$ and long-term $\mathrm{pH}_{\text {stat }}$ leaching tests for metal mobilization from solid matrices. Acta Hydroch., Hydrob., 1999, 27, 223-229.

[62] van Herreweghe S., Arsenic and heavy metal contaminated soils caused by ore treatment activities, a differentiated speciation approach. PhD thesis, Katholieke Universiteit Leuven, Geology Department, 2002

[63] van Herreweghe S., Swennen R, Cappuyns V., Vandecasteele $C$., Chemical associations of heavy metals and metalloids in contaminated soils near former ore treatment plants: a differentiated approach with emphasis on $\mathrm{pH}_{\text {stat }}$-leaching. J. Geochem. Explor., 2002, 76, 113-138

[64] Shtiza A., Swennen R., Cappuyns V., Tashko A., ANC / BNC and mobilization of $\mathrm{Cr}$ from polluted sediments in function of $\mathrm{pH}$ changes. Environ. Geol., 2009, 56, 1663-1678

[65] Hursthouse A.S., The relevance of speciation in the remediation of the soils and sediments contaminated by metallic elements - an overview and examples from Central Scotland, UK. J. Environ. Monitor., 2001, 3, 49-60

[66] Walter I., Martínes F., Cala V., Heavy metal speciation and phytotoxic effects of three representative sewages sludges for agricultural uses. Environ. Pollut., 2006, 139, 507-514

[67] Landner L., Reuther R., A critical review of current knowledge on metals in society and environment. Kluwer Academic Publishers, Dordrecht, the Netherlands, 2004

[68] Kotas J., Stasicka Z., Chromium occurrence in the environment and methods of its speciation. Environ. Pollut., 2000, 107, 263-283

[69] USEPA., Chromium Hexavalent (Colorimetric). Environmental Protection Agency, Washington, D.C., 1995

[70] Burke Th., Fagliano J., Goldoft M., Hazen R.E., Iglewicz R., McKee Th., Chromite Ore Processing Residue in Hudson Country, New Jersey. Environmental Health Perspectives, 1991, 92, 131-137

[71] Whalley C., Hursthouse A., Rowlatt S., Iqbal-Zahid P., Vaughan H., Durant R., Chromium speciation in natural waters draining contaminated land, Glasgow, U.K. Water, Air Soil Pollution, 1999, 112, 389-405

[72] Farmer J.G., Thomas R.P., Graham M.C., Geelhoed J.S., Lumsdon D.G., Paterson E., Chromium speciation and fractionation in ground and surface waters in the vicinity of chromite ore processing residue disposal sites. J. Environ. Monit., 2002, 4, 235-243

[73] Hillier S., Roe M.J., Geelhoed J.S., Fraser A.R.,
Farmer J.G., Paterson E., Role of quantitative mineralogical analysis in the investigation of sites highly contaminated by chromate ore processing residue. Sci. Tot. Environ., 2003, 308, 195-210

[74] Abbas Z., Steenari B-M., Lindqvist O., A study of $\mathrm{Cr}(\mathrm{VI})$ in ashes from fluidized bed combustion of municipal solid waste: leaching, secondary reactions and the applicability of some speciation methods. Waste Manage., 2001, 21, 725-739

[75] Shtiza A., Geogene and anthropogene signatures of chromium species occurring on industrial sites in Albania. PhD dissertation, Katholieke Universiteit Leuven. Geology Department, 2007

[76] Shtiza A., Swennen R., Tashko A., Chromium speciation and existing natural attenuation conditions in lagoonal and pond sediments in the former chemical plant of Porto-Romano (Albania). Environ. Geol., 2008, 53, 1107-1128

[77] Goldstein J., Newbury D., Joy DC., Echlin P., Lyman C., Lifshin E., Scanning electron microscopy and x-ray microanalysis. Plenum Press, New York, 2003

[78] Farges F., Brown G.E., Rehr J.J., Coordination chemistry of $\mathrm{Ti}(\mathrm{IV})$ in silicates glasses and melts: I. XAFS study of titanium coordination in oxide model compounds. Geochim. Cosmochim. Ac., 1996, 60, 30233038

[79] Zachara J.M., Ainsworth C.C., Brown G.E., Catalano J.G., McKinley J.P., Qafoku O., Smith S.C., Szecsody J.E., Traina S.J., Warner J.A. 2004. Chromium speciation and mobility in a high level nuclear waste vadose zone plume. Geochim. Cosmochim. Ac, 2004. 68, 1330

[80] Mattigod S.V., Sposito G., Chemical modelling of trace metals equilibrium in contaminated soil solutions using the computer program GEOCHEM. In: Jenne E.A. (Ed.), Chemical modelling in aqueous systems. ACS No 93 American Chemical Society, Washington D.C., 1979, 837-856

[81] USEPA., MINTEQ2, an equilibrium metal speciation model: users manual. USEPA, EPA/600/3-87/012. Athens, GA. 1987

[82] Allison J.D., Brown D.S., Novogradac K.J., MINTEQA2/PRODEFA2: A geochemical assessment model for environmental systems-version 3.0 user's manual: Environmental Research Laboratory, Office of Research and Development, U.S. Environmental Protection Agency, Athens, Georgia, 1990

[83] Parkhurst D.L., User's guide to PHREEQC: A computer program for speciation, reaction-path, advective-transport, and inverse geochemical calculations: U.S. Geological Survey Water-Resources Investigations Report 95-4227, 1995, 1-143 
[84] Meeussen J.C.L., ORCHESTRA: An object oriented framework for implementing chemical equilibrium models. Environ. Sci. Technol., 2003, 37, 1175-1182

[85] Gustafsson J.P., Visual MINTEQ version 2.4, A chemical equilibrium model for the calculation of metal speciation, solubility equilibria etc. for environmental systems. 2006, Website: http://www.lwr.kth.se/ English/OurSoftware/vMINTEQ/index.htm

[86] Theocharopoulos S., Wagner G., Sprengart J., Mohr M-E., Desaules A., Muntau H., Christou M., Quevauviller Ph., European soil sampling guidelines for soil pollution studies. Sci. Tot. Environ., 2001, 264, 51-62

[87] Wagner G., Mohr M-E., Sprengart J., Desaules A., Muntau H., Theocharopoulos S., Quevauviller Ph., Objectives, concept, and design of the CEEM soil project. Sci. Tot. Environ., 2001, 264, 3-15
[88] Fairbrother A., Wenstel R., Sappington K., Wood W., Framework for metals risk assessment. Ecotox. Environ. Safe., 2007, 68, 145-227

[89] Nagourney S.J., Wilson S.A., Buckley B., Kingston H.M., Yang S.Y., and Long S.E., Development of a Standard Reference Material for CrVI in Contaminated Soil. J. Anal. Atom. Spectrom., 2008, 23,15501554

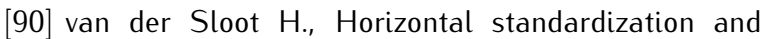
harmonization of leaching tests methods for waste, secondary raw materials construction materials and (contaminated) soil. Proceedings of WASCON SanSebastian, Spain, 2003

[91] Filgueiras A.V., Lavilla I., Bendicho C., Chemical sequential extraction for metal partitioning in environmental solid samples. J. Env. Monit. 2002, 4, 823-857 